\title{
Improved Corneal Toxicity and Permeability of Tranilast by the Preparation of Ophthalmic Formulations Containing Its Nanoparticles
}

\author{
Noriaki Nagai ${ }^{1}$, Hikaru Ono ${ }^{1}$, Miho Hashino ${ }^{1}$, Yoshimasa Ito $^{1 *}$, Norio Okamoto ${ }^{2}$ \\ and Yoshikazu Shimomura ${ }^{2}$ \\ ${ }^{1}$ Faculty of Pharmacy, Kinki University, 3-4-1 Kowakae, Higashi-Osaka, Osaka, 577-8502, Japan. \\ ${ }^{2}$ Department of Ophthalmology Kinki University Faculty of Medicine, 377-2 Ohno-Higashi, Osaka-Sayama, Osaka, 589-8511, Japan.
}

\begin{abstract}
We prepared ophthalmic formulations containing $0.5 \%$ tranilast (TL) nanoparticles using $0.005 \%$ benzalkonium chloride (BAC), 0.5\% D-mannitol, and 2-hydroxypropyl- $\beta$-cyclodextrin (HP $\beta C D)$, and investigated their usefulness in the ophthalmologic field by evaluating corneal toxicity and permeability. TL nanoparticles were prepared using zirconia beads and Bead Smash 12, which allowed the preparation of high quality dispersions containing $0.5 \%$ TL nanoparticles (particle size, $34 \pm 20 \mathrm{~nm}$, means \pm S.D.). Dispersions containing TL nanoparticles are tolerated better by human corneal epithelium cells than a commercially available $0.5 \%$ TL preparation (RIZABEN ${ }^{\circledR}$ eye drops). In addition, the addition of TL nanoparticles to the dispersions does not affect the antimicrobial activity of BAC against Escherichia coli (ATCC 8739), and the corneal penetration of TL from dispersions containing TL nanoparticles was significantly higher than in the case of the commercially available $0.5 \% \mathrm{TL}$ eye drops. It is possible that dispersions containing TL nanoparticles will show increased effectiveness against ocular inflammation, and that ocular drug delivery systems using drug nanoparticles may lead to an expansion of their usefulness for therapy in the ophthalmologic field.
\end{abstract}

Key words: nanoparticle, tranilast, eye drops, transcorneal penetration, corneal stimulation

\section{INTRODUCTION}

The ophthalmic application of drugs is the primary route of administration for the treatment of various eye diseases, and is well-accepted by patients; however, in traditional formulations only small amounts of the administered drug $(0.5 \%)$ penetrate the cornea to reach the desired intraocular tissue due to corneal barriers and dilution caused by lacrimation $^{1-3)}$. Consequently, there is a need for frequent instillation of concentrated solutions to obtain the desired therapeutic effect in both the anterior and posterior hemispheres of the eye. However, the frequent administration of drugs can cause corneal damage as well as undesirable side effects resulting from the systemic absorption of drugs through the nasolacrimal duct ${ }^{4,5)}$. Therefore, it is very important to increase the effectiveness of drugs by enhancing their bioavailability ${ }^{6}$. In order to overcome these problems and increase ocular drug bioavailability, several strategies including the preparation of viscous solutions, micro/ nanoparticles and hydrogels have been developed and in- vestigated $^{1,4,7-10)}$. In the case of viscous solutions, numerous studies have demonstrated that they do not possess sufficient mechanical strength to resist the ocular clearance mechanism, and offer only a transient improvement in ocular residence time ${ }^{11)}$. On the other hand, it has been reported that the penetration capability of drugs across the cornea can be significantly improved by decreasing the particle size using nanoparticles ${ }^{3,9,12)}$. Implants fabricated using the biodegradable polymer PLGA[poly (DL-lactideco-glycolide) ] with mean particle diameters of $50-200 \mathrm{~nm}$ have been widely utilized as carriers for bioactive molecules and present a possible solution to the limitations surrounding ocular drug penetration ${ }^{13-16)}$. It is expected that ophthalmic drug systems using nanoparticles may provide an alternative strategy for increasing ocular drug penetration $^{13-16)}$

Tranilast (TL), $N$ - (3',4'-dimethoxycinnamoyl) anthranilic acid, is a synthetic, multi-potential, anti-allergic, and antifibrotic drug reported to have various effects both in vitro

\footnotetext{
*Correspondence to: Yoshimasa Ito, Faculty of Pharmacy, Kinki University, 3-4-1 Kowakae, Higashi-Osaka, Osaka, 577-8502, Japan.

E-mail: itoyoshi@phar.kindai.ac.jp

Accepted October 10, 2013 (recieved for review May 25, 2013)

Journal of Oleo Science ISSN 1345-8957 print / ISSN 1347-3352 online

http://www.jstage.jst.go.jp/browse/jos/ http://mc.manusriptcentral.com/jjocs
} 
as well as in vivo ${ }^{17}$. The variety of TL functions published to date include the suppression of collagen synthesis by fibroblasts via the down-regulation of cytokine release from monocytes/macrophages ${ }^{18}$, the transcriptional and translational inhibition of matrix metallo-proteases in lipopolysaccharide-stimulated neutrophils ${ }^{19)}$, and the suppression of monocyte/macrophage infiltration and associated myocardial fibrosis in the deoxycorticosterone acetate/salt hypertensive rats ${ }^{20)}$. Because the solubility of TL in water is very low $(14.5 \mu \mathrm{g} / \mathrm{ml})$, it is generally dissolved with the aid of a surface-active agent; in such a solution, TL has been widely used in the ophthalmic field as RIZABEN ${ }^{\oplus}$ eye drops $0.5 \%$ solution, and provides effective therapy for ocular inflammation. However, this preparation of TL does not provide effective therapy for uveitis or after cataract surgery because the amount of TL in the intraocular area is low. Therefore, it is possible that enhancing the transcorneal penetration of TL will increase its effectiveness against ocular inflammation (as can occur in uveitis and after cataract surgery), and lead to an expansion of its therapeutic usage in the ophthalmologic field.

Preservatives are essential additives in ophthalmic preparations, and the most common preservative in preparations used to treat glaucoma and ocular surface diseases is BAC, most often at a concentration of $0.01 \%$ (range, 0.005 $-0.02 \%)$ in topical multi-dose solutions ${ }^{21}$. Although, the BAC is known to cause corneal stimulation, we have previously shown that this side effect can be prevented by the addition of D-mannitol to the preparation ${ }^{22)}$. In this study, we made preparations of TL nanoparticles containing BAC and D-mannitol, and investigated their usefulness in the ophthalmologic field by evaluating corneal toxicity and permeability.

\section{EXPERIMENTAL}

\subsection{Animals and reagents}

Male rabbits were housed under standard conditions (12 $\mathrm{h} / \mathrm{d}$ fluorescent light $(07: 00-19: 00), 25^{\circ} \mathrm{C}$ room temperature), and allowed free access to a commercial diet (CR-3, Clea Japan Inc., Tokyo, Japan) and water. All procedures were performed in accordance with the Kinki University Faculty of Pharmacy Committee Guidelines for the Care and Use of Laboratory Animals and the Association for Research in Vision and Ophthalmology resolution on the use of animals in research. TL (TL microparticles)were kindly donated by Kissei Pharmaceutical Co., Ltd. (Nagano, Japan) . 2-Hydroxypropyl- $\beta$-cyclodextrin (HP $\beta C D$, average molar substitution, 0.6; average MW, 1380) was purchased from Nihon Shokuhin Kako Co., Ltd. (Tokyo, Japan). Commercially available $0.5 \%$ TL eye drops $\left(\right.$ RIZABEN $^{\circledR}$ eye drops $0.5 \%, \mathrm{TL}_{\text {commercially }}$ eye drops) were obtained from Kissei Pharmaceutical Co., Ltd., and benzalkonium chloride
(BAC) was provided by Kanto Chemical Co., Inc. (Tokyo, Japan). Mannitol(D-mannitol) was purchased from Wako Pure Chemical Industries, Ltd. (Osaka, Japan). All other chemicals used were of the highest purity commercially available.

\subsection{Preparation of ophthalmic dispersions containing TL nanoparticles}

TL nanoparticles were prepared using zirconia beads and Bead Smash 12 (a bead mill, Wakenyaku Co. Ltd, Kyoto, Japan). Scheme 1 shows the preparation method for ophthalmic dispersions containing TL used in this study. Zirconia beads (diameter: $2 \mathrm{~mm}$ ) were added to TL microparticles (solid, original TL) containing BAC or mannitol, and the mixture was crushed with a Bead Smash 12 for $30 \mathrm{sec}\left(1,500 \mathrm{rpm}, 4^{\circ} \mathrm{C}\right)$. The mixture was dispersed in saline with or without $5 \%$ HP $\beta C D$, and crushed with the Bead Smash $12\left(5,500 \mathrm{rpm}, 60 \mathrm{sec}, 4^{\circ} \mathrm{C}\right)$ using zirconia beads (diameter: $0.1 \mathrm{~mm}$ ). The compositions of the dispersions containing TL are shown in Table 1. A $0.5 \%$ TL dispersion is equivalent to $15.3 \mathrm{mM}$ TL; the $\mathrm{pH}$ of both ophthalmic dispersions containing TL micro- or nanoparticles was 6 . The particle size was measured using a nanoparticle size analyzer SALD-7100 (Shimadzu Corp., Kyoto, Japan; refractive index 1.60-0.10i).

\subsection{Stability of ophthalmic dispersions containing TL}

TL concentrations in the samples were determined by a High Performance Liquid Chromatography (HPLC) method. Ten microliters of filtrate was added to $100 \mu$ methanol containing $0.3 \mu \mathrm{g}$ ethyl $p$-hydroxybenzoate (internal standard), and the mixture was filtered through a Chromatodisk 4A (pore size $0.45 \mu \mathrm{m}$, Kurabo Industries Ltd., Osaka, Japan). The solution $(10 \mu \mathrm{l})$ was injected into an Inertsil ${ }^{\circledR}$ ODS-3 $(3 \mu \mathrm{m}$, column size: $2.1 \mathrm{~mm} \times 50 \mathrm{~mm})$ column (GL Science Co., Inc., Tokyo, Japan) on a Shimadzu LC-10AD system equipped with a column oven CTO-6A (Shimadzu Corp., Kyoto, Japan). The mobile phase consisted of acetonitrile/50 mM ammonium acetate(20/80) at a flow rate of $0.25 \mathrm{ml} / \mathrm{min}$; the column temperature was $35^{\circ} \mathrm{C}$, and the wavelength for detection was $230 \mathrm{~nm}$. Three milliliters of ophthalmic dispersions containing TL as described in Table 1 were incubated in $5 \mathrm{ml}$ test tubes in the dark at $20^{\circ} \mathrm{C}$ for $72 \mathrm{~h}$, after which $50 \mu \mathrm{l}$ of sample solution was withdrawn from $5 \mathrm{~mm}$ under the surface at the indicated time intervals (total height of liquid, $4 \mathrm{~cm}$ ).

\subsection{Antimicrobial activity of dispersions containing TL nanoparticles}

Dispersions containing TL nanoparticles $\left(\mathrm{TL}_{\text {nano }}\right)$ as described in Table 1 were tested for antimicrobial activity against Escherichia coli (E. coli, ATCC 8739). The organism was selected based on Japanese Pharmacopoeia(JP) test protocols, and the minimal inhibitory concentration 
Table 1 Ophthalmic Formulations of Particle Dispersions containing TL.

\begin{tabular}{lccccc}
\hline \multirow{2}{*}{ Formulation } & \multicolumn{5}{c}{ Content $(\mathrm{w} / \mathrm{v} \%)$} \\
\cline { 2 - 5 } & TL microparticles & BAC & D-Mannitol & HP $\beta C D$ & Treatment \\
\hline Milled-TL & 0.5 & - & - & - & Bead mill \\
Milled-TL & 0.5 & 0.005 & - & - & Bead mill \\
Milled-TL $_{\text {BAC-Mannitol }}$ & 0.5 & 0.005 & 0.5 & - & Bead mill \\
TL $_{\text {micro }}$ & 0.5 & 0.005 & 0.5 & 5.0 & - \\
$\mathrm{TL}_{\text {nano }}$ & 0.5 & 0.005 & 0.5 & 5.0 & Bead mill \\
\hline
\end{tabular}

Dispersions containing TL were prepared according to Scheme 1.

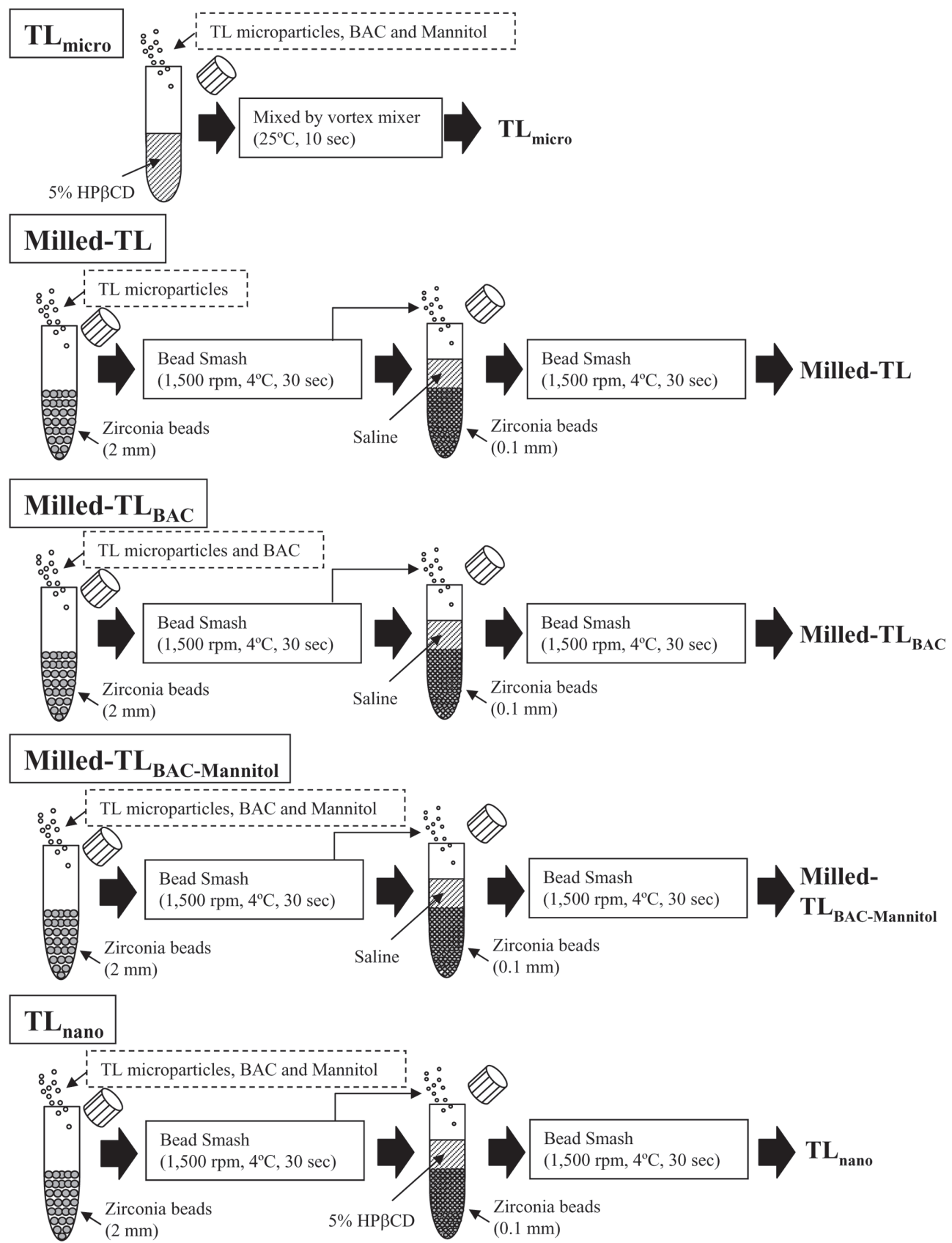

Scheme 1 Preparation Procedures of Ophthalmic Dispersions containing TL. 
(MIC) was determined from the lowest concentration showing antimicrobial activity ${ }^{23)}$. According to the standard methodology, the bulk dilution was split into $10 \mathrm{ml}$ aliquots, which were each inoculated with between $10^{5}$ and $10^{6}$ colony-forming units (CFU)/ml of E. coli (1 organism per aliquot) and incubated in the presence of vehicle (solution containing $0.005 \% \mathrm{BAC}, 0.5 \%$ mannitol and $5 \% \mathrm{HP} \beta \mathrm{CD}$ ) and $0.5 \%$ TL-containing dispersions at $20^{\circ} \mathrm{C}$ to $25^{\circ} \mathrm{C}$. The inoculated solutions were sampled and counted on days 2 , 7,14 and 28. One milliliter aliquots were serially diluted in phosphate buffer $(\mathrm{pH} 7.2)$, plated in duplicate on soybeancasein digest agar (Casein soya bean digest agar for JP general test, Wako, Osaka, Japan), and incubated at $31^{\circ} \mathrm{C}$ for 3 days. Raw data counts were converted to $\log$ (CFU) values. Since the samples were diluted at least 1:10 at the time of testing, $10 \mathrm{CFU}$ reduction is the lowest sensitivity allowed by the test. In the measurement of MIC, the samples $(20 \mu \mathrm{l})$ were mixed with $180 \mu \mathrm{l} E$. coli solution (5× $10^{4}(\mathrm{CFU}) /$ well) in 96-well microplates (IWAKI, Chiba, Japan), and incubated at $35^{\circ} \mathrm{C}$ for $24 \mathrm{~h}$.

\subsection{Cell culture and treatment}

The immortalized human corneal epithelial cell line HCE-T developed by Araki-Sasaki et $a l^{24)}$ was used in this study. HCE-T cells were cultured in Dulbecco's modified Eagle's medium/Ham's F12 (GIBCO, Tokyo, Japan) containing $5 \%(\mathrm{v} / \mathrm{v})$ heat-inactivated fetal bovine serum, $0.1 \mathrm{mg} / \mathrm{mL}$ streptomycin and $1000 \mathrm{IU} / \mathrm{ml}$ penicillin (GIBCO, Tokyo, Japan). For experiments, HCE-T cells $\left(1 \times 10^{4}\right.$ cells/well $)$ were seeded in 96-well microplates (IWAKI, Chiba, Japan). Ophthalmic dispersions containing $0.5 \%$ TL or commercially available $0.5 \%$ TL eye drops $(200 \mu \mathrm{l})$ were added to the cell cultures one day after seeding, and the cells were stimulated for $0-120 \mathrm{sec}^{25}$. Following stimulation, culture medium containing TetraColor One (SEIKAGAKU Co. Tokyo, Japan) was added, the absorbance(Abs) at $490 \mathrm{~nm}$ was measured, and cell viability was calculated according to the manufacturer's instructions as represented by equation 1(Eq. 1):

$$
\text { Cell viability }(\%)=\mathrm{Abs}_{\text {stimulation }} / \mathrm{Abs}_{\text {non-stimulation }} \times 100 \quad \text { Eq. } 1
$$

where $\mathrm{Abs}_{\text {stimulation }}$ shows the Abs of samples treated with ophthalmic dispersions containing $0.5 \%$ TL or commercially available $0.5 \%$ TL eye drops. The $\mathrm{Abs}_{\text {non-stimulation }}$ shows the Abs of samples treated with saline.

\subsection{In vitro transcorneal penetration of ophthalmic disper- sions containing TL}

The in vitro transcorneal penetration of ophthalmic dispersions containing $0.5 \%$ TL or commercially available $0.5 \%$ TL eye drops was examined using the method of Iwata et $a l .{ }^{26)}$ Adult Japanese albino rabbits weighing 2.5 to $3.0 \mathrm{~kg}$ were killed by injecting a lethal dose of pentobarbital into the marginal ear vein. The eyes were removed and the corneas were carefully separated from other ocular tissues. The individual corneas were placed on a methacrylate cell designed for transcorneal penetration studies. The side of the chamber (donor chamber) exposed to the exterior surface of the cornea was filled with an ophthalmic dispersion containing $0.5 \%$ TL or commercially available $0.5 \%$ TL eye drops. The other side of the chamber (reservoir chamber) was filled with $10 \mathrm{mM}$ HEPES buffer ( $\mathrm{pH} 7.4)$ containing $136.2 \mathrm{mM} \mathrm{NaCl}, 5.3 \mathrm{mM} \mathrm{KCl}, 1.0 \mathrm{mM} \mathrm{K}_{2} \mathrm{HPO}_{4}$, $1.7 \mathrm{mM} \mathrm{CaCl}_{2}$ and $5.5 \mathrm{mM}$ glucose. The experiments were performed at $35^{\circ} \mathrm{C}$ for $6 \mathrm{~h}$. Fifty microliter aliquots of sample solution were withdrawn from the reservoir chamber at the indicated time intervals and replaced with the same volume of buffer. The TL concentrations in the samples were determined by HPLC method described above. Corneal viability was monitored by measuring corneal thickness $(0.0625 \mathrm{~cm}$, average for 5 rabbits; no significant changes in thickness were observed over the $6 \mathrm{~h}$ period). The obtained data were analyzed according to the following equations:

$$
\begin{array}{lc}
J_{c}=\frac{K_{m} \cdot D \cdot C_{\mathrm{TL}}}{\delta}=K_{p} \cdot C_{\mathrm{TL}} & \text { Eq. } 2 \\
\tau=\frac{\delta^{2}}{6 D} & \text { Eq. } 3 \\
Q_{t}=J_{c} \cdot A \cdot(t-\tau) & \text { Eq. } 4
\end{array}
$$

where $J_{c}$ is the TL penetration rate, $K_{m}$ is the cornea/preparation partition coefficient, $D$ is the diffusion constant within the cornea, $C_{\mathrm{TL}}$ is the TL content in the ophthalmic preparation, $\tau$ is the lag time, $\delta$ is thickness of the cornea $(0.0625 \mathrm{~cm}$, average of 5 rabbits $), Q_{t}$ is the total amount of TL appearing in the reservoir solution at time $t$, and $A$ is the effective area of the cornea $\left(0.78 \mathrm{~cm}^{2}\right) . J_{c}$ and $\tau$ were estimated by fitting each penetration profile to Eq. 4. The penetration coefficient through the cornea, $K_{p}$, is given by $J_{c} / C_{\mathrm{TL}}$. A nonlinear least-squares computer program was employed for the calculation ${ }^{25)}$.

\subsection{Photochemical resistance of ophthalmic dispersions containing TL}

The $0.5 \% \mathrm{TL}_{\text {nano }}$ preparation as described in Table 1 and $0.5 \%$ liquid TL in dimethyl sulfoxide were tested for photodegradability under fluorescent light $(400-700 \mathrm{~nm})$. The TL preparations were exposed to $58 \mathrm{~W} / \mathrm{m}^{2}$ for $12 \mathrm{~h}$, after which the TL concentrations in $50 \mu \mathrm{l}$ samples were determined by the HPLC method described above.

\subsection{Statistical analysis}

All values are presented as mean \pm standard deviation (S.D.) or standard error of the mean (S.E.). Unpaired Student's $t$-test was used to evaluate statistical differences, and multiple groups were evaluated by one-way analysis of variance followed by Dunnett's multiple comparison. $P$ values less than 0.05 were considered significant. 


\section{RESULTS}

\subsection{Preparation of Ophthalmic Dispersions containing TL Nanoparticles}

Figure 1 shows the particle size distribution and mean particle diameter of dispersions containing $0.5 \%$ TL as described in Table 1. The TL microparticles were milled by the bead mill method to a mean particle size of $8.58 \pm 6.59$ $\mu \mathrm{m}$ (mean \pm S.D. $)$. Although, the mean particle size of TL was decreased by the addition of BAC, the decrease in particle size was small. On the other hand, TL nanoparticles obtained by the addition of HP $\beta C D$ had a mean particle size of $34 \pm 20 \mathrm{~nm}$ (mean \pm S.D.). Figure 2 shows the stability of dispersions containing 0.5\% TL as described in Table
1. The $\mathrm{TL}_{\text {micro }}$ preparation precipitated $4 \mathrm{~h}$ after preparation. The stability of TL dispersions was increased when the bead mill method was used in conjunction with BAC addition with the Milled-TL $\mathrm{L}_{\mathrm{BAC}}$ preparation precipitating 36 $\mathrm{h}$ after preparation. On the other hand, the addition of $\mathrm{HP} \beta C D$ enhanced the stability of the TL dispersion $\left(\mathrm{TL}_{\text {nano }}\right)$, and precipitation was not observed until $72 \mathrm{~h}$ after preparation. Figure 3 shows the antimicrobial activities of $\mathrm{TL}_{\text {nano }}$ preparations. The antimicrobial activity of the $0.005 \%$ BAC solution was high with no $E$. coli detected 2 days after treatment. The $\mathrm{TL}_{\text {nano }}$ preparation also showed high antimicrobial activity approximately equal to that of the $0.005 \%$ BAC solution.
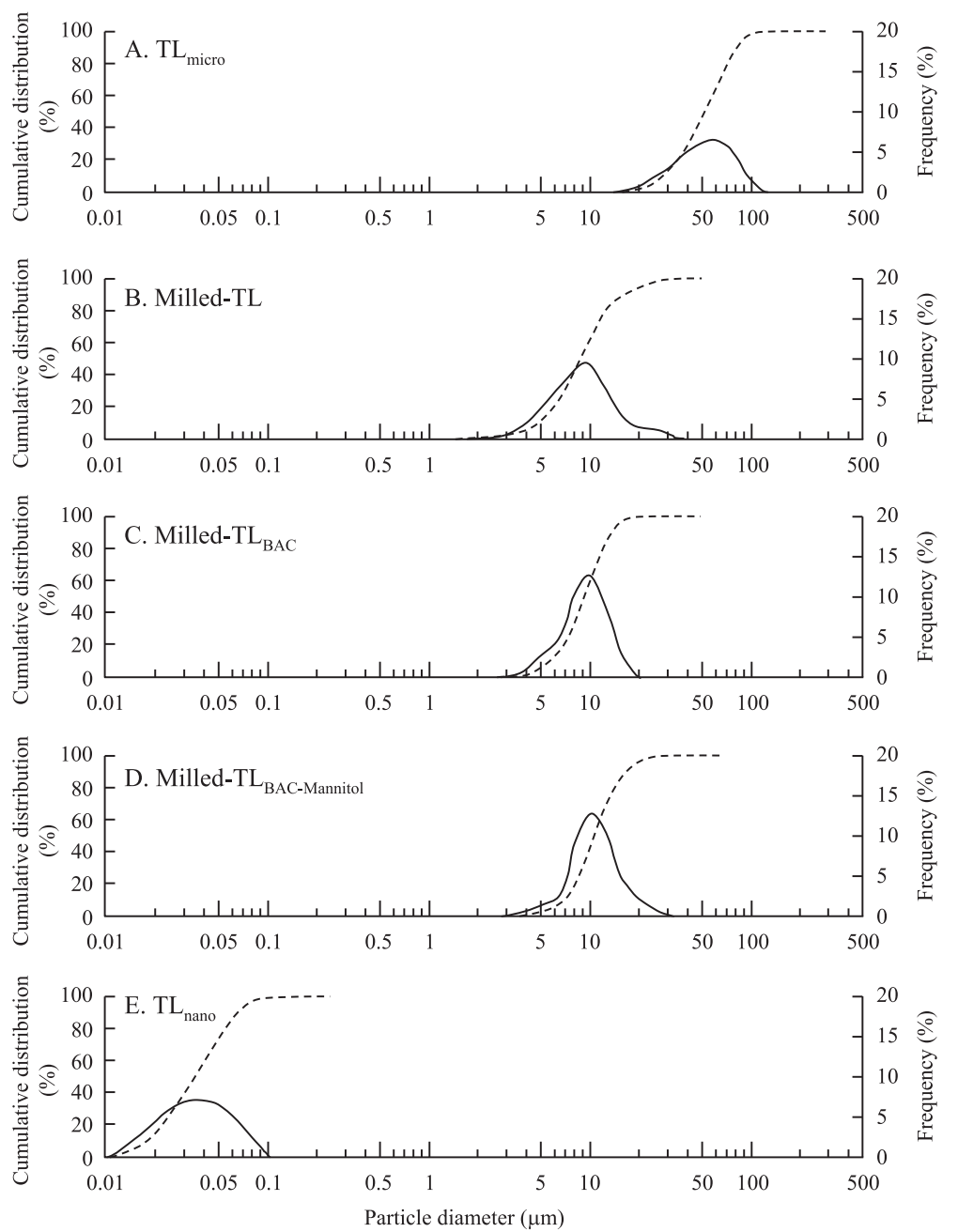

Fig. 1 Cumulative Size Distribution and Frequency of 0.5\% TL Dispersions with or without BAC, Mannitol and $\mathrm{HP} \beta C D$. The compositions of the TL dispersions are shown in Table 1. Particle size was determined using a nanoparticle size analyzer SALD-7100 (refractive index 1.60-0.10i). A: cumulative distribution and frequency of TL microparticles (particle size $52.1 \pm 23.4 \mu \mathrm{m}$ ), B: cumulative distribution and frequency of Milled-TL (particle size $8.58 \pm 6.59 \mu \mathrm{m}$ ), C: cumulative distribution and frequency of Milled-TL $\mathrm{TLC}_{\mathrm{BAC}}$ (particle size $8.76 \pm 4.21$ $\mu \mathrm{m})$, D: cumulative distribution and frequency of Milled-TL $\mathrm{TAC}_{\text {BACMnitol }}$ (particle size $12.5 \pm 4.10 \mu \mathrm{m}$ ), E: cumulative distribution and frequency of $\mathrm{TL}_{\text {nano }}$ (particle size $0.034 \pm 0.020 \mu \mathrm{m}$ ). The data are presented as means \pm S.D. 


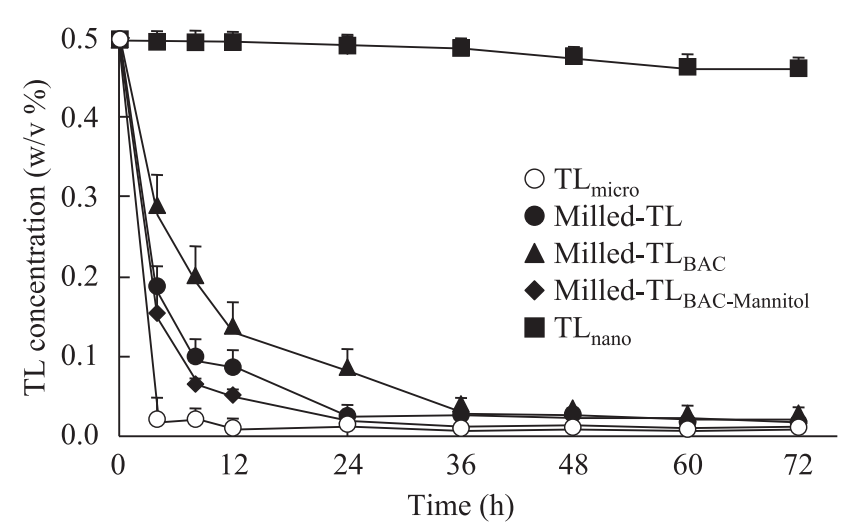

Fig. 2 Stability of $0.5 \%$ TL Dispersions with or without BAC, Mannitol and HP $\beta C D$. 0.5\% TL dispersions were kept in the dark at $20^{\circ} \mathrm{C}$ for $72 \mathrm{~h}$, and the amounts of remaining TL were determined at the indicated time points. The compositions of the TL dispersions are shown in Table 1. The data are presented as means \pm S.E. of 5 independent samples.

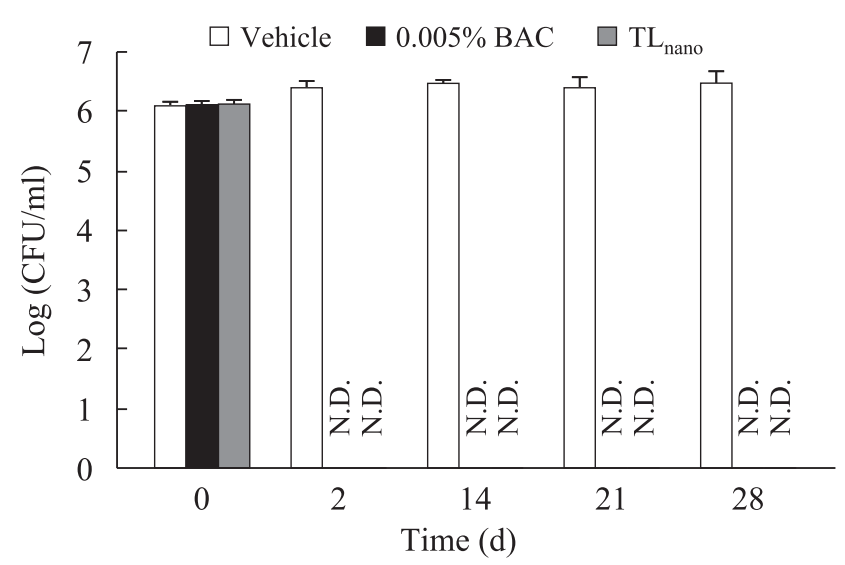

Fig. 3 Evaluation of the Antimicrobial Activities of Dispersions with and without TL Nanoparticles. Dispersions containing vehicle alone, vehicle plus $0.005 \%$ BAC, or vehicle plus $0.005 \%$ BAC and $0.5 \% \mathrm{TL}$ nanoparticles $\left(\mathrm{TL}_{\text {nano }}\right.$ ) were tested for antimicrobial activity against $E$. coli (ATCC 8739). Raw data counts were converted to $\log _{10}$ values, and are presented as means \pm S.E. of 5 independent experiments. N.D. indicates not detected. MIC: BAC, $15 \mu \mathrm{g} / \mathrm{ml}$; $\mathrm{TL}_{\text {nano }}, 15 \mu \mathrm{g} / \mathrm{ml}$.

3.2 Corneal Stimulation and Transcorneal Penetration of Ophthalmic Dispersions containing TL Nanoparticles

Figure 4 shows the changes in the viability of HCE-T cells following treatment with $\mathrm{TL}_{\text {commercially }}$ eye drops or $\mathrm{TL}_{\text {micro }}$ or $\mathrm{TL}_{\text {nano }}$. The viability of HCE-T cells treated with $\mathrm{TL}_{\text {conmercially }}$ eye drops for 60 or $120 \mathrm{sec}$ was approximately $68.7 \%$ or $62.2 \%$, respectively. On the other hand, the via-

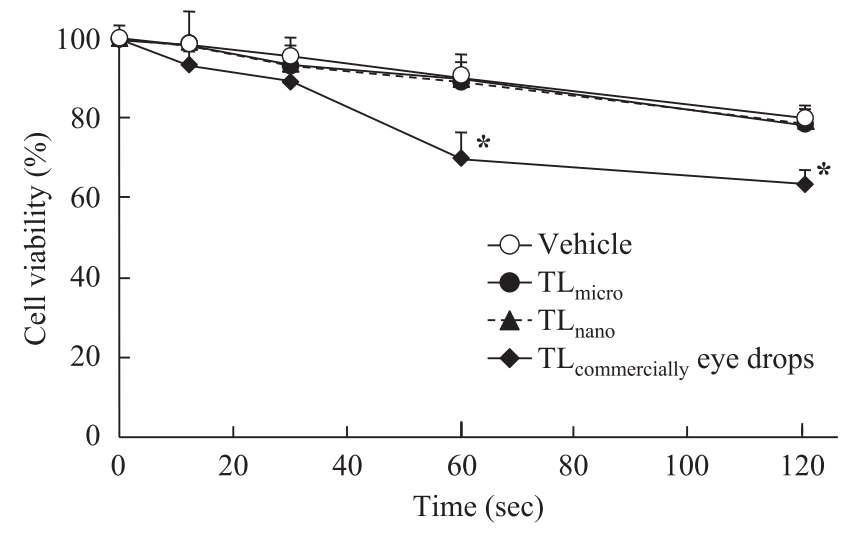

Fig. 4 Effects of Dispersions containing 0.5\% TL Nanoparticles on the Viability of HCE-T Cells. HCE-T cells in 96-well microplates were treated with commercially available TL eye drops $\left(\mathrm{TL}_{\text {commercially }}\right.$ eye drops) or dispersions containing TL microparticles $\left(\mathrm{TL}_{\text {micro }}\right)$ or TL nanoparticles $\left(\mathrm{TL}_{\text {nano }}\right)$ for 0 - $120 \mathrm{sec}$. Cell viability was calculated using TetraColor One according to Eq. 1 in EXPERIMENTAL. The data are presented as means \pm S.E. of $5-10$ experiments. ${ }^{*} p<0.05$, vs. $\mathrm{TL}_{\text {nano. }}$.

bility of HCE-T cells treated with $\mathrm{TL}_{\text {nano }}$ was higher than in the case of the $\mathrm{TL}_{\text {commercially }}$ eye drops, and no differences in the viability of HCE-T cells treated with $\mathrm{TL}_{\text {micro }}$ or $\mathrm{TL}_{\text {nano }}$ were observed. Figure 5 shows the in vitro transcorneal penetration of $\mathrm{TL}_{\text {commercially }}$ eye drops, $\mathrm{TL}_{\text {micro }}$, and $\mathrm{TL}_{\text {nano }}$ through rabbit corneas, and Table 2 summarizes the pharmacokinetic parameters calculated from the in vitro transcorneal penetration data. In the case of $\mathrm{TL}_{\text {micro }}$, no $\mathrm{TL}$ was detected in the reservoir chamber until $4 \mathrm{~h}$ after administration. On the other hand, transcorneal penetration in the case of $\mathrm{TL}_{\text {commercially }}$ eye drops began after a lag time of $1.93 \mathrm{~h}$ with a subsequent penetration rate of $15.2 \pm 3.74$ $\mathrm{nmol} / \mathrm{cm}^{2} / \mathrm{h}$ (mean \pm S.E. .). Penetration from $\mathrm{TL}_{\text {micro }}$ was lower than that from the commercially available TL eye drops, while the $\mathrm{TL}$ penetration rate from $\mathrm{TL}_{\text {nano }}(36.8 \pm$ $1.65 \mathrm{nmol} / \mathrm{cm}^{2} / \mathrm{h}$, mean \pm S.E. ) was significantly higher in comparison with $\mathrm{TL}_{\text {commercially }}$ eye drops.

\section{DISCUSSION}

In this study, we prepared ophthalmic formulations containing TL nanoparticles, and investigated their usefulness in the ophthalmologic field by evaluating their corneal toxicity and permeability.

BAC has been used as an effective preservative and is indispensable in the preparation of eye drops. However, BAC has also been shown to be highly toxic both in vitro and in vivo due to its stimulatory effect on epithelial cell death ${ }^{27,28)}$. 
A
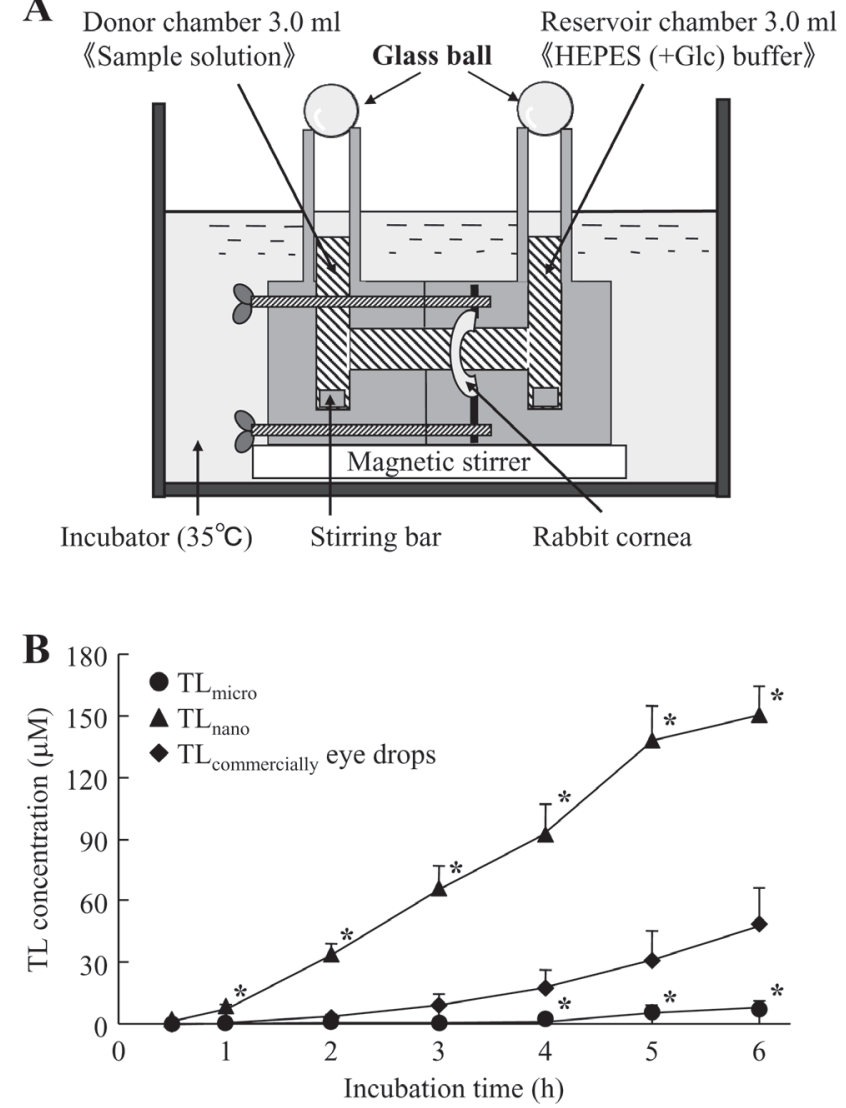

Fig. 5 In vitro Transcorneal Penetration of Dispersions containing TL Nanoparticles. A: Image of the methacrylate cell designed for the transcorneal penetration study. B: Transcorneal penetration of dispersions containing TL nanoparticles. The donor chamber facing the exterior surface of the cornea was filled with commercially available $\mathrm{TL}$ eye drops $\left(\mathrm{TL}_{\text {commercially }}\right.$ eye drops) or dispersions containing $\mathrm{TL}$ microparticles $\left(\mathrm{TL}_{\text {micro }}\right)$ or nanoparticles $\left(\mathrm{TL}_{\text {nano }}\right)$. The data are presented as the means \pm S.E. of 3-4 rabbit corneas. ${ }^{*} p<0.05$, vs. commercially available $\mathrm{TL}$ eye drops $\left(\mathrm{TL}_{\mathrm{com}}\right.$ mercially eye drops).

BAC is a quaternary ammonium compound that has been shown to hasten the drying of the tear film ${ }^{29,30)}$, worsen preexisting dry ey ${ }^{31}$, and affect both the cornea and conjunctiva ${ }^{32)}$. In addition, BAC is a pro-inflammatory or proapoptotic mediator ${ }^{33)}$ because it induces oxidative stress $^{34-36)}$ or significantly alters precorneal mucins ${ }^{37)}$. Clinically, these iatrogenic effects are found most frequently in eye drops used to treat long-term pathologies and inflammation. The side effects of BAC seem to be both dose- and time-dependent, increasing with larger amounts used for longer periods. On the other hand, we previously reported that the addition of D-mannitol prevents corneal stimulation by
$\mathrm{BAC}^{22)}$, and change in chemical structure was not observed by addition of the BAC and D-mannitol ${ }^{22)}$. Therefore, we attempted the preparation of a TL dispersion containing BAC and mannitol using the bead mill method (Milled$\left.\mathrm{TL}_{\mathrm{BAC}-\mathrm{Mannitol}}\right)$. Although, the TL particle size in Milled$\mathrm{TL}_{\text {BAC-Mannitol }}(12.5 \pm 4.90 \mu \mathrm{m})$ was lower than that of TL microparticles $(52.1 \pm 23.4 \mu \mathrm{m}$, means \pm S.D. $)$, the particle size was not sufficiently small to be called a nanoparticle(Fig. 1), and the stability of Milled-TL $L_{\mathrm{BAC}-M a n n i t o l}$ was also low (Fig. 2). Mori $e t a l{ }^{38)}$ reported that adsorption to the surface of cyclodextrin decreases the cohesion of nanoparticulate solids, and we previously reported that the addition of HP $\beta C D$ is suitable for the preparation of nanoparticles using mill methods ${ }^{39)}$. Furthermore, Jansen et al. ${ }^{40)}$ have reported no observable irritation of the eye membrane by solutions containing HP $\beta C D$ at concentrations less than $12.5 \%$. Therefore, we used $5 \%$ HP $\beta$ CD to prepare TL nanoparticle dispersions in this study. The addition of $5 \%$ $\mathrm{HP} \beta \mathrm{CD}$ resulted in a smaller TL particle size and an increased stability of the resulting dispersions containing TL nanoparticles $\left(\mathrm{TL}_{\text {nano }}\right)$. The antimicrobial activity is important in ophthalmic preparations. $\mathrm{TL}_{\text {nano }}$ containing $0.005 \%$ BAC showed high antimicrobial activity with an MIC equal to that of a $0.005 \%$ BAC solution(Fig. 3). These results suggest that the TL nanoparticle dispersions in this study do not affect the antimicrobial activity of BAC, and that the chemical structure shows no difference between TL microparticles and nanoparticles.

Next, we evaluated the dispersions containing TL nanoparticles in terms of corneal damage and transcorneal penetration using HCE-T cells and rabbit corneas (Fig. 4 and 5). The viability of $\mathrm{HCE}-\mathrm{T}$ cells treated with $\mathrm{TL}_{\text {nano }}$ was higher than that of cells treated with $\mathrm{TL}_{\text {commercially }}$ eye drops, and no difference in cell viability was observed between $\mathrm{TL}_{\text {micro }}$ and $\mathrm{TL}_{\text {nano }}$ (Fig. 4). In the in vitro transcorneal penetration experiment, no TL was detected in the reservoir chamber until $4 \mathrm{~h}$ after the introduction of $\mathrm{TL}_{\text {micro }}$ into the donor chamber (Fig. 5); however, the lag time for the $\mathrm{TL}_{\text {commercially }}$ eye drops was $1.93 \mathrm{~h}$, and the penetration rate was obviously higher than that from $\mathrm{TL}_{\text {micro }}$ (Table 2). On the other hand, the penetration from $\mathrm{TL}_{\text {nano }}$ was significantly higher than that from $\mathrm{TL}_{\text {commercially }}$ eye drops. Since $\mathrm{TL}_{\text {nano }}$ contains $\mathrm{HP} \beta C D$, the data suggest that the higher rate of transcorneal penetration from $\mathrm{TL}_{\text {nano }}$ is a result of the increased solubility of TL due to its association with HP $\beta C D$. Also, the TL penetration rate from dispersions containing $0.5 \%$ TL nanoparticles, $0.005 \%$ BAC, $0.5 \%$ mannitol and $5 \%$ HP $\beta C D$ was approximately 2 -fold higher than that from dispersions containing $0.25 \%$ TL nanoparticles, $0.005 \%$ $\mathrm{BAC}, 0.5 \%$ mannitol and $5 \% \operatorname{HP} \beta \mathrm{CD}\left(J_{c}, 15.2 \pm 1.33 \mathrm{nmol} /\right.$ $\mathrm{cm}^{2} / \mathrm{h}$, means \pm S.E., $\mathrm{n}=3$ ). These results indicate that the state of the TL nanoparticle itself, that is TL without the formation of the inclusion complex in the presence of $\mathrm{HP} \beta C D$, is the main factor affecting transcorneal penetra- 
Table 2 Pharmacokinetic Parameters for the in vitro Transcorneal Penetration of Dispersions containing TL Nanoparticles.

\begin{tabular}{lccc}
\hline & $\mathrm{TL}_{\text {micro }}$ & \multicolumn{1}{c}{$\mathrm{TL}_{\text {nano }}$} & $\mathrm{TL}_{\text {commercially }}$ eye drops \\
\hline$J_{c}\left(\mathrm{nmol} / \mathrm{cm}^{2} / \mathrm{h}\right)$ & $2.31 \pm 0.47$ & $36.8 \pm 1.65^{* 1,2}$ & $15.2 \pm 3.74^{* 1}$ \\
$k_{p}\left(\times 10^{-3} / \mathrm{h}\right)$ & $0.53 \pm 0.31$ & $2.41 \pm 0.11^{* 1,2}$ & $0.99 \pm 0.24$ \\
$k_{m}$ & $0.41 \pm 0.05$ & $0.16 \pm 0.01^{* 1}$ & $0.18 \pm 0.03^{* 1}$ \\
$\tau(\mathrm{h})$ & $2.94 \pm 0.33$ & $0.70 \pm 0.04^{* 1,2}$ & $1.93 \pm 0.15^{* 1}$ \\
$D\left(\times 10^{-4} \mathrm{~cm}^{2} / \mathrm{h}\right)$ & $2.27 \pm 0.29$ & $9.37 \pm 0.64^{* 1,2}$ & $3.44 \pm 0.30^{* 1}$ \\
\hline
\end{tabular}

Parameters were calculated according to Eqs. 2-4 (see EXPERIMENTAL). $\mathrm{TL}_{\text {micro }}$, dispersion containing $\mathrm{TL}$ microparticles; $\mathrm{TL}_{\text {nano }}$, $\mathrm{TL}$ dispersion containing nanoparticles; $\mathrm{TL}_{\text {commercially }}$ eye drops, commercially available TL eye drops. The data are presented as means \pm S.E. of 3-5 independent rabbit corneas. ${ }^{1} p<0.05$, vs. $\mathrm{TL}_{\text {micro }}$ for each category. $*^{2} p<0.05$, vs. commercially available $\mathrm{TL}$ eye drops $\left(\mathrm{TL}_{\text {commercially }}\right.$ eye drops) for each category.

tion from $\mathrm{TL}_{\text {nano. }}$. In addition, liquid $\mathrm{TL}$ is known to be highly photodegradable, while TL nanoparticles (100 - 200 nm) show high photochemical resistance ${ }^{41)}$. We also investigated the photochemical resistance of $0.5 \% \mathrm{TL}_{\text {nano }}$ under fluorescent light $(400-700 \mathrm{~nm})$. Liquid TL in dimethyl sulfoxide was found to be photodegradable when exposed to 58 $\mathrm{W} / \mathrm{m}^{2}$ for $12 \mathrm{~h}$ (remaining content $67.8 \pm 4.0 \%$ vs. before photo illumination, mean \pm S.E. $n=3$ ); however, a high degree of photochemical stability was observed for $\mathrm{TL}_{\text {nano }}$ (remaining content 98.6 $\pm 2.7 \%$ vs. before photo illumination, mean \pm S.E. $n=3$ ). Taken together, $\mathrm{TL}_{\text {nano }}$ may provide effective therapy for patients with ocular inflammation requiring the long-term application of eye drops (as can occur in uveitis and after cataract surgery). Further studies are needed to elucidate the structure of the delivery system. Therefore, we are now investigating the structure of the delivery system for TL nanoparticles by scanning electron microscopy.

\section{CONCLUSIONS}

In the present study, we attempted to establish a preparation method for drug nanoparticles, and succeeded in preparing high quality dispersions containing TL nanoparticles (particle size, $34 \pm 20 \mathrm{~nm}$, mean \pm S.D.). The dispersions containing TL nanoparticles were tolerated better by human corneal epithelium cells than the commercially available $0.5 \%$ TL eye drops (RIZABEN ${ }^{\circledR}$ eye drops). In addition, the state of the dispersions containing TL nanoparticles did not affect the antimicrobial activity of BAC against $E$. coli, and the corneal penetration of TL from dispersions containing TL nanoparticles was significantly higher than that from commercially available TL eye drops. It is possible that dispersions containing TL nanoparticles will show increased effectiveness in treating ocular inflammation, and an ocular drug delivery system using drug nanoparticles may expand their usage for therapy in the ophthalmologic field.

\section{References}

1) Diebold, Y.; Jarrin, M.; Saez, V.; Carvalho, E. L. S.; Orea, M.; Calonge, M.; Seijo, B.; Alonso, M. J. Ocular drug delivery by liposome-chitosan nanoparticle complexes (LCS-NP) . Biomaterials 28, 1553-1564(2007).

2) Baba, K.; Tanaka, Y.; Kubota, A.; Kasai, H.; Yokokura, S. Nakanishi, H.; Nishida, K. A method for enhancing the ocular penetration of eye drops using nanoparticles of hydrolysable dye. J. Control. Release 153, 278-287 (2011).

3) Li, X.; Zhang, Z.; Li, J.; Sun, S.; Weng, Y.; Chen, H. Diclofenac/biodegradable polymer micelles for ocular applications. Nanoscale 4, 4667-4673 (2012).

4) Asasutjarit, R.; Thanasanchokpibull, S.; Fuongfuchat, A.; Veeranodha, S. Optimization and evaluation of thermoresponsive diclofenac sodium ophthalmic in situ gels. Int. J. Pharm. 411, 128-135(2011).

5) Mahmoud, A. A.; El-Feky, G. S.; Kamel, R.; Awad, G. E. A. Chitosan/sulfobutylether-[beta]-cyclodextrin nanoparticles as a potential approach for ocular drug delivery. Int. J. Pharm. 413, 229-236(2011).

6) Ammar, H. O.; Salama, H. A.; Ghorab, M.; Mahmoud, A. A. Nanoemulsions as potential ophthalmic delivery systems for orzolamide hydrochloride. AAPS Pharm. Sci. Tech. 10, 808-819(2009).

7) El-Kamel, A. H. In vitro and in vivo evaluation of Pluronic F127-based ocular delivery system for timolol maleate. Int. J. Pharm. 241, 47-55(2002).

8) Sultana, Y.; Aqil, M.; Ali, A. Ion-activated, Gelrite ${ }^{\circledR}$ based in situ ophthalmic gels of pefloxacin mesylate: comparison with conventional eye drops. Drug Deliv. 13, 215-219 (2006).

9) Gupta, H.; Aqil, M.; Khar, R. K.; Ali, A.; Bhatnagar, A.; Mittal, G. Biodegradable levofloxacin nanoparticles for 


\section{Preparation of Ophthalmic Formulations containing Tranilast Nanoparticles}

sustained ocular drug delivery. J. Drug Target. 19, 409-417 (2011).

10) Casolaro, M.; Casolaro, I.; Lamponi, S. Stimuli-responsive hydrogels for controlled pilocarpine ocular delivery. Eur. J. Pharm. Biopharm. 80, 553-561 (2012).

11) Davies, N. M.; Fair, S. J.; Hadgraft, J.; Kellaway, I. W. Evaluation of mucoadhesive polymers in ocular drug delivery. I. Viscous solutions. J. Pharm. Sci. 8, 10391043 (1991).

12) Rafie, F.; Javadzadeh, Y.; Javadzadeh, A. R.; Ghavidel, L. A.; Jafari, B., Moogooee, M., Davaran, S. In vivo evaluation of novel nanoparticles containing dexa-methasone for ocular drug delivery on rabbit eye. Curr. Eye Res. 35, 1081-1089 (2010).

13) Cohen, S.; Yoshioka, T.; Lucarelli, M.; Hwang, L. H.; Langer, R. Controlled delivery systems for proteins based on poly (lactic/glycolic acid) microspheres. Pharm. Res. 8, 713-720(1991).

14) Tomoda, K.; Watanabe, A.; Suzuki, K.; Inagi, T.; Terada, H.; Makino, K. Enhanced transdermal permeability of estradiol using combination of PLGA nanoparticles system and iontophoresis. Colloids Surf. B Biointerfaces, 97, 84-89 (2012).

15) Tomoda, K.; Terashima, H.; Suzuki, K.; Inagi, T.; Terada, H.; Makino, K. Enhanced transdermal delivery of indomethacin using combination of PLGA nanoparticles and iontophoresis in vivo. Colloids Surf. B Biointerfaces, 92, 50-54(2012).

16) Tomoda, K.; Terashima, H.; Suzuki, K.; Inagi, T.; Terada, H.; Makino, K. Enhanced transdermal delivery of indomethacin-loaded PLGA nanoparticles by iontophoresis. Colloids Surf. B Biointerfaces, 88, 706-710 (2011).

17) Pfab, T.; Hocher, B. Tranilast and hypertensive heart disease: further insights into mechanisms of an antiinflammatory and anti-fibrotic drug. J. Hypertens., 22, 883-886 (2004).

18) Suzawa, H.; Kikuchi, S.; Ichikawa, K.; Koda, A. Inhibitory action of tranilast, an anti-allergic drug, on the release of cytokines and PGE2 from human monocytesmacrophages. Jpn. J. Pharmacol., 60, 85-90 (1992).

19) Shimizu, T.; Kanai, K.; Kyo, Y.; Asano, K.; Hisamitsu, T.; Suzaki, H. Effect of tranilast on matrix metalloproteinase production from neutrophils in-vitro. J. Pharm. Pharmacol. 58, 91-99(2006).

20) Kagitani, S.; Ueno, H.; Hirade, S.; Takahashi, T.; Takata, M.; Inoue, H. Tranilast attenuates myocardial fibrosis in association with suppression of monocyte/macrophage infiltration in DOCA/salt hypertensive rats. $J$. Hypertens. 22, 1007-1015(2004).

21) Pisella, P. J.; Fillacier, K.; Elena, P. P.; Debbasch, C.; Baudouin, C. Comparison of the effects of preserved and unpreserved formulations of timolol on the ocular surface of albino rabbits. Ophthalmic. Res. 32, 3-8
(2000).

22) Nagai, N.; Murao, T.; Oe, K.; Ito, Y.; Okamoto, N.; Shimomura, Y. In vitro evaluation for corneal damages by anti-glaucoma combination eye drops using human corneal epithelial cell (HCE-T). Yakugaku Zasshi 131, 985-991 (2011).

23) Yakuji Nippo Ltd. Japanese Pharmacopoeia. Tokyo. Maruzen Co., Ltd, 15 (2006).

24) Araki-Sasaki, K.; Ohashi, Y.; Sasabe, T.; Hayashi, K.; Watanabe, H.; Tano, Y.; Handa, H. An SV40-immortalized human corneal epithelial cell line and its characterization. Invest. Ophthalmol. Vis. Sci., 36, 614-621 (1995).

25) Nagai, N.; Ito, Y.; Okamoto, N.; Shimomura, Y. Decrease in corneal damage due to benzalkonium chloride by the addition of sericin into timolol maleate eye drops. J. Oleo Sci. 62, 159-166 (2013).

26) Iwata, S.; Osada, Y.; Ogino, H. Aspect on corneal permeability of bupranolol. YAKUGAKU ZASSI 100, $402-$ 406 (1980).

27) Rolando, M.; Brezzo, G.; Giordano, P.; Campagna, P.; Burlando, S.; Calabria, G. "The Lacrimal System," ed. by Van, Bijsterweld, O. P.; Lemp, M. A.; Spinelli, D. Kagler \& Ghedini, Amsterdam, pp. 89-91 (1991).

28) Debbasch, C.; Pisella, P. J.; De, Saint, Jean, M.; Rat, P.; Warnet, J. M.; Baudouin, C. Mitochondrial activity and glutathione injury in apoptosis induced by unpreserved and preserved beta-blockers on Chang conjunctival cells. Invest. Ophthalmol. Vis. Sci. 42, 25252533 (2001).

29) Wilson, W. S.; Duncan, A. J.; Jay, J. L. Effect of benzalkonium chloride on the stability of the precorneal tear film in rabbit and man. Br. J. Ophthalmol. 59, 667669 (1975).

30) Kuppens, E. V.; de, Jong, C. A.; Stolwijk, T. R.; De Keizer, R. J.; Van, Best, J. A. Effect of timolol with and without preservative on the basal tear turnover in glaucoma. Br. J. Ophthalmol. 79, 339-342(1995).

31) Burstein, N. L. Preservative cytotoxic threshold for benzalkonium chloride and chlorhexidine digluconate in cat and rabbit corneas. Invest. Ophthalmol. Vis. Sci. 19, 308-313 (1980).

32) De, Saint, Jean, M.; Debbasch, C.; Brignole, F.; Rat, P.; Warnet, J. M.; Baudouin, C. Toxicity of preserved and unpreserved antiglaucoma topical drugs in an in vitro model of conjunctival cells. Curr. Eye Res. 20, 85-94 (2000).

33) De, Saint, Jean, M.; Brignole, F.; Bringuier, A. F. Effects of benzalkonium chloride on growth and survival of Chang conjunctival cells. Invest. Ophthalmol. Vis. Sci. 40, 619-630 (1999).

34) Guenoun, J. M.; Baudouin, C.; Rat P.; Pauly, A.; Warnet, J. M.; Briqnole, Baudouin, F. In vitro study of inflammatory potential and toxicity profile of latanoprost, 
travoprost, and bimatoprost in conjunctiva-derived epithelial cells. Invest. Ophthalmol. Vis. Sci. 46, 2444-2450 (2005).

35) Guenoun, J. M.; Baudouin, C.; Rat, P.; Pauly, A.; Briqnole-Baudouin, F. In vitro comparison of cytoprotective and antioxidative effects of latanoprost, travoprost, and bimatoprost on conjunctiva-derived epithelial cells. Invest. Ophthalmol. Vis. Sci. 46, 4594-4599 (2005).

36) Debbasch, C.; Brignole, F.; Pisella, P. J.; Warnet, J. M., Rat, P.; Baudouin, C. Quaternary ammoniums and other preservatives' contribution in oxidative stress and apoptosis on Chang conjunctival cells. Invest. Ophthalmol. Vis. Sci. 42, 642-652(2001).

37) Chung, S. H.; Lee, S. K.; Cristol, S. M.; Lee, D. W.; Seo, K. Y.; Kim, E. K. Impact of short-term exposure of commercial eyedrops preserved with benzalkonium chloride on precorneal mucin. Mol. Vis. 12, 415-421 (2006).
38) Mori, K.; Yoshioka, N.; Kondo, Y.; Takeuchi, T.; Yamashita, H. Catalytically Active, Magnetically Separable, and Water-soluble FePt Nanoparticles Modified with Cyclodextrin for Aqueous Hydrogenation Reactions. Green Chem. 11, 1337-1342 (2009).

39) Okamoto, N.; Ito, Y.; Nagai, N.; Murao, T.; Takiguchi, Y.; Kurimoto, T.; Mimura, O. Preparation of ophthalmic formulations containing cilostazol as an anti-glaucoma agent and improvement in its permeability through the rabbit cornea. J. Oleo Sci. 59, 423-430 (2010).

40) Jansen, T.; Xhonneux, B.; Mesens, J.; Borgers, M. Betacyclodextrins as vehicles in eye-drop formulations: an evaluation of their effects on rabbit corneal epithelium. Lens Eye Toxic. Res. 7, 459-468(1990).

41) Kawabata, Y.; Yamamoto, K.; Debari, K.; Onoue, S.; Yamada, S. Novel crystalline solid dispersion of tranilast with high photostability and improved oral bioavailability. Eur. J. Pharm. Sci. 39, 256-262 (2010). 